\title{
The Effect of Task Repetition on Complexity and Accuracy of Iranian High-intermediate EFL Learners' Narrative Writing Performance
}

\author{
Leyli Azizzadeh (Corresponding Author) \\ Department of English Language Teaching, Islamic Azad University, Ahar Branch \\ Ahar-Tabriz Rd.2 Km, East Azerbaijan, Iran \\ E-mail: 1.azizzadeh10@yahoo.com \\ Leila Dobakhti \\ Tabriz Islamic Art University, Tabriz, Iran \\ E-mail: 1.dobakhti@tabriziau.ac.ir
}

Received: 16-07-2014

doi:10.7575/aiac.ijalel.v.4n.2p.17
Accepted: 19-09-2014

Published: 01-03-2015

URL: http://dx.doi.org/10.7575/aiac.ijalel.v.4n.2p.17

\begin{abstract}
Developments in the area of task-based language teaching (TBLT) research have heightened the need to focus on the task implementation factors in the sense that they are effective in successful language performance to occur. The present study aimed to examine the effect of task repetition, as one of the task implementation variables, on Iranian high-intermediate English as a foreign language (EFL) learners' narrative writing performance. To this end, a pretest/post-test quasi-experimental design was applied; 40 participants, with 18 to 25 years of age, were non-randomly selected and considered as two groups of the experimental and control ones. Both groups took a pre-test to ensure their homogeneity in narrative writing skill. Then, for 14 sessions, the experimental group was engaged in repetitive practice of narrative writing tasks. Three weeks after the end of the treatment, both groups performed the two post-tests. The results of independent samples $t$-tests showed that the experimental group significantly outperformed the control one in regard with complexity on the two post-test phases $(p<.05)$, however; the results were not significant in the case of accuracy. The findings have important pedagogical implications for EFL learners and teachers, as well as useful future research directions in EFL writing for the researchers.
\end{abstract}

Keywords: Task repetition, Complexity, Accuracy, Narrative writing, EFL learner

\section{Introduction}

Writing is an important language skill for EFL learners to develop their language knowledge. As Chastain (1988) has noted, writing is not only a way of communication through which language learners can express what's going on in their minds, but also it can help language learning with its "unique features" (p. 244). However, writing is considered as the most difficult language skill because it needs the spontaneous practice of a number of very different abilities (Harris, 1969).

As Biria and Jafari (2013) argue, in Iranian educational system even in private language institutes, students receive little practice in EFL writing, and writing still remains a big barrier for most of them. This may resulted from the use of inappropriate teaching methods of writing (Silva, 1990). Unfortunately, in spite of the developments in the teaching methods of writing in different EFL contexts, product-oriented approach has been the dominate method of teaching in Iranian EFL writing classes for decades (Birjandi \& Malmir, 2009).

In product-oriented instruction, as Kim (2001) has noted, learners have little opportunity to edit, organize, and reformulate their texts when performing writing; and thereby, they fail to achieve a high level of EFL writing proficiency. Furthermore, teachers' attitude towards correcting learners' writing is just time consuming and unrewarding, because learners usually neglect the instructors' feedback of error correction (Howrey \& Tanner, 2009). Hence, in order to help learners master this skill and know it a valuable one in its own right, more attention to the process of writing through task-based approaches seems necessary.

According to Hamadouche (2010) in this approach, writing as a process is not a step-by step activity; rather, it involves moving back and forth between several stages to be accomplished. However, from another point of view, tasks are essentially meaning-centered, which cause learners to prioritize meaning over the form when handling tasks. Meanwhile, it is said that task repetition, as one of the task implementation factors, has the potential to free up learners' attention to focus on the formal and systemic aspects of language (Ahmadian, 2011; Ellis, 2005, 2009; Muranoi, 2007).

However, there is little empirical work on the language learning opportunities created through task repetition in EFL writing (Larsen-Freeman, 2006; Zohrabi \& Abasvand, 2014). This study attempts to fill the gap in the literature by probing into the application of task repetition to improve Iranian EFL learners' narrative writing performance in regard 
with complexity and accuracy. In Iranian context writing is particularly important, as learners apply EFL writing more than speaking for international communicative purposes (Birjandi \& Malmir, 2009).

To achieve the purpose of this study, the following questions are formulated:

$\mathbf{R Q}_{1}$. Does using task repetition have any significant effect on Iranian high-intermediate EFL learners' narrative writing performance in terms of complexity?

$\mathbf{R Q}_{2}$. Does using task repetition have any significant effect on Iranian high-intermediate EFL learners' narrative writing performance in terms of accuracy?

$\mathbf{R Q}_{3}$. Does the effect of task repetition transferred to Iranian high-intermediate EFL learners' performance of the new narrative task as measured in terms of complexity and accuracy?

\section{Review of Related Literature}

As Ellis (2003) asserts, through engaging in language production, learners "maybe able to utilize their own internal resources, via using them in production, to both construct and complexify their interlanguages" (p. 115). Hence, output practice may afford learners with opportunity to get aware of their linguistic problems and manipulate their language focus, and in so doing promotes acquisition (Muranoi, 2007).

It is of prime importance in language learning to achieve a high degree of fluency, complexity, and accuracy in learner performance (Ellis, 2009). However, as Skehan (1998) has hypothesized, it is not easy to achieve these aspects of performance simultaneously, especially when one performing a cognitively demanding task. This is known as trade-off hypothesis. Based on this hypothesis, different aspects of language performance compete for limited cognitive processing resources, and as a result attention to one aspect means the decrease of attendance to the other aspects. Some studies have shown that the trade-off effect is mostly between complexity and accuracy (e.g. Foster \& Skehan, 1996; Skehan, 1998). As Foster and Skehan (1996) point out, the focus of both complexity and accuracy is on form, but there is a significant difference in emphasis. That is, while complexity connects with change and the opportunities for development and growth in the interlanguage system, accuracy emphasizes control at a particular interlanguage level. It is suggested that if learners prioritize complexity in performing the tasks, accuracy will be suffered. Conversely, the focus on performing more accurately will leads to a less complex performance (ibid.).

In Skehan, Xiaoyue, Qian, and Wang's (2012) term, although tasks and task variables are important starting points in decreasing cognitive processing pressure, but their actual impact on performance and pedagogy can be varied under the conditions they are performed. Task planning is one of those task implementation conditions that, as Ellis (2005) argues; is the integral part of any spoken and written language use, even the one which appears effortless and automatic. In his position, planning is considered essentially as "a problem solving activity" which concerns choosing the appropriate linguistic devices in order to satisfy the audience (ibid., p. 3). Among the different types of task planning, rehearsal planning or task repetition is said to be the most effective type of planning in language learning (Bygate, 2001; Bygate \& Samuda, 2005).

Bygate (2001) defines task repetition as the repeated use of the same or a similar communication task which provide learners with the opportunity to build on their previous attempt as performing the task repeatedly. Similarly, Ellis's (2009) assumption of task repetition is that performance of a task at the first time is regarded as planning for the subsequent performance of the same task. Bygate and Samuda (2005) declare that rehearsal effect of task repetition offers the learners certain processing opportunities not available in the other types of planning. In particular, repetition is considered as a form of preparedness. In the same vein, Ellis (2003) asserts that the learners' previous experience of the speaking or writing task may release their processing capacity to focus on the language of expressing their ideas. This may result in enhancement in the quantity, fluency, and complexity of their language output (ibid.).

The underlying assumption, based on Bygate (1999), is that human beings always improve their ability to exert communicative situations through repeated encounters with similar demands (e.g. small talk, telephone conversations). During the initial performance, they primarily focus on the message content, while searching their memory for appropriate language to carry out the task. In this way, the familiarity with useful message content and language knowledge for handling the task are established. On subsequent occasions, this familiarity provide enough time and awareness to switch attention from message content to the selection and monitoring of appropriate language, which may improve fluency, complexity and/or accuracy (Bygate, 1999). This is in line with Adam's (2003) suggestion that decreasing the processing demands through task repetition is a possible source for the learners' incorporation of more target-like forms in the second writing of the same story.

The theoretical implications behind task repetition can be represented by referring to language production models (e.g. Kellog's (1996) model of writing production, and Skehan's (1998) cognition hypothesis). According to Kellog (1996), any written text production is the ultimate result of three basic interactive and recursive systems involvement. They are: formulation, execution, and monitoring. All of these systems entail two main processes. Formulation involves: (a) planning for the aim of establishing goals along with generating and organizing ideas in a coherent order, (b) translation which is related to the selection of lexical units and syntactic frames in relation to the ideas of planning phase. The second system is Execution and involves: (a) programming, and (b) executing. During the programming process, the writer pushes what he/she has in mind, into a paper or on the monitor and in the executing, the writer reaches to the actual production of the output. The third and last system is Monitoring which involves: (a) reading, in which the writer read what he/she has produced, and (b) editing, in which the writer can edit the text in terms of micro aspects of the text such as linguistic errors or macro aspects of the text such as paragraph and text organization. Kellog (ibid.) has stressed that these processes are activated concurrently, "although the extent to which this is achievable depends on working 
memory" (p. 14). Ellis (2005) argues that rehearsal may lead to all-round improvements when the task is repeated and thereby, may enable learners to attend to all three components in the model.

One of the important issues in regard with task repetition is the issue of transfer, that is, whether the effects of task repetition extend to the performance of a new task, and thereby, contribute to interlanguage development and second language (L2) acquisition (Ahmadian, 2011; Ellis, 2009). Ellis (2009) believes that some kinds of additional intervention are required for acquisition to take place, suggesting that simply repeating a task may not assist acquisition. One of the possibilities is hypothesized by Bygate (2001) in the sense that more opportunities for repetitive practice of the tasks are required for acquisition to take place. Another explanation is that learners need some kind of feedback on their initial performance of the performed task (Sheppard, 2006, as cited in Ellis, 2009).

Most of the Studies about the effect of task repetition on language performance focused on oral output (e.g. Ahmadian, 2011; Bygate, 2001; Bygate \& Samuda, 2005; Eliasi \&VahidiBorji, 2013; Gass, Mackey, Fernandez, \& Alvarez-Torres, 1999). Bygate (2001) investigated the changes in: a) the repeated performance of the same tasks that participants had performed 10 weeks earlier, b) the performance of a new task of the same type that they had practiced over the 10 weeks and one they had not practiced; and c) the differences in their overall performance of the narrative and interview task types. The results showed that task repetition had significant effects on fluency and complexity of the learners' oral performance in the same task. However, this study found no statistically significant effect on accuracy of the same repeated task. Additionally, the findings suggested that practicing the same task type did not affect new versions of the same task type. Larsen-Freeman (2006) explored the ongoing emergence of complexity, fluency, and accuracy in the oral and written production of five high-intermediate Chinese learners of English over a six-month period. Based on qualitative and quantitative analyses, it was found that the five learners became more fluent, accurate and complex language performers through engaging in task repetition treatment. In a recent study, Zohrabi and Abbasvand (2014) investigated the effect of task repetition on accuracy and complexity of writing performance of intermediate EFL learners. The results of immediate post-test revealed that task repetition had a significant effect on the accuracy and complexity of the experimental group's performance. Also, a delayed post-test was administered which showed the long-term effects of task repetition even one month after the end of the treatment.

\section{Method}

A pre-test/post-test quasi-experimental design was used for this study, since the students were previously placed in different classes and it was impossible to change their arrangement. Writing performance in terms of complexity and accuracy had the role of dependent variable upon which task repetition as the independent variable had the possible effect.

\subsection{Participants}

From the population of 83 female high-intermediate EFL learners who were studying English in a language institute in Tabriz, 40 learners were selected non-randomly through convenient sampling to participate in the study. The nonrandomized design which involves intact groups has the benefits of a high degree of face validity (Mackey \& Gass, 2005, as cited in Zoghi, 2012) and external validity (Dimitrov \& Rumrill, 2003, as cited in Zoghi, 2012). There were 20 EFL learners in each of the two classes. They were introduced as high-intermediate EFL learners according to the language institute's standards and the institutional placement tests that they had taken (Oxford Placement Test). However, the Nelson (300D) test was applied to confirm the homogeneity of the participants in terms of general English proficiency. One of the above stated classes was randomly considered as the experimental group and the other was the control one. The participants' age range was between 18 and 25. At the time that the study was conducted, the participants had eight hours of English per week- five hours for listening and speaking and three hours for reading and writing- in the language institute. They were all bilinguals of Azeri and Persian, learning English as their foreign language. None of them had been to any English speaking country.

\subsection{Instrumentations}

Nelson (300D) test of English homogeneity: The test was taken from Flower and Norman's (1976) book, and consisted of 50 multiple-choice items, including reading, grammar, vocabulary, and pronunciation, to each of which one point was assigned. The participants had 40 minutes to answer it.

The pre- and post-test narrative writing tasks: Two narrative writing tasks including two sets of wordless picture stories which were chosen from Heaton's (1975) book were used as the prompts to elicit written narratives of the participants during the pre- and post-test phases. These wordless picture stories have been successfully used in linguistic research to elicit both EFL/ESL oral and written narratives (e.g. Ellis \& Yuan, 2004; Tavakoli \& Skehan, 2005). The stories were relatively complex to engage the participants in negotiation of meaning and form simultaneously. These two tasks were considered equivalent in Ellis and Yuan's (2004) study. Also, two small-scale pilot studies were conducted before the beginning of the study to insure the appropriate task condition for the main study. Results of the studies revealed that the first test task could be performed in 18 minutes by producing at least 180 words, and the second test task required writing at least 200 words within 20 minutes.

Materials: Seven narrative writing tasks based on the wordless picture stories from Heaton's (1975) book were applied during the treatment phase.

\subsection{Procedure}

Obtaining the verbal permission of the manager of the language institute, two classes, each including 20 highintermediate EFL learners, were selected. Both groups were taught by their own instructors in the institute. However, 
the instructors were trained about two hours by the researcher for clarifying the procedure of the study and about what they were expected to do during the study. Since the participants had no previous experience of performing narrative writing task, as stated by their instructors, they received one-day instruction from their instructors about how to perform a narrative task before the study began. Then, a week before beginning the treatment, both groups were pre-tested to ascertain their homogeneity in the narrative writing skill in terms of complexity and accuracy.

A week after conducting the pre-test and assuring the homogeneity of the two groups in narrative writing performance $(p>.05)$, the experimental group was treated with repetitive practicing of seven narrative writing tasks for 14 sessions (Narrative tasks: 1,2 - 3,4 - 1,5 - 2,6 - 3,7 - 4,5 - 6,7). Each week, they did two narrative writing tasks. The treatment sessions were more intensive, since the participants were EFL learners who were not exposed to English out of the classroom and this could compensate for that shortcoming.

On the other hand, the participants in the control group did not engage in any repetitive practice of narrative writing task. They were just taught with traditional ways of teaching EFL writing in which the learners were provided with a variety of rules of writing in regard with punctuation procedures, filling the gap exercises, etc.

Three weeks after the treatment, both groups did the narrative writing task that they performed in the pre-test phase. Also, they performed another narrative task that was equivalent with the pre-test task. This story was different in content to examine the transference effect of task repetition to the new narrative task. All the conditions of performing the test tasks were identical except that for the second test task, based on the findings of the pilot study, the allocated time was 20 minutes. Finally, both groups' textual products were analyzed in terms of complexity and accuracy.

To ensure the inter-rater reliability, $20 \%$ of the data from both the pre-test and post-tests were coded by an independent rater. As Mackey and Gass (2005) state, "it is possible to establish confidence in rater reliability with as little as $10 \%$ of the data" (p. 243). The results of inter-rater reliability test (simple percentage agreement) for the written narrative tasks of the pre- and post-test sessions showed above $86 \%$ agreement, and thus were satisfactory (ibid.).

\subsection{Measures}

The participants' written productions of the pre- and post-test phases were analyzed for terminable units (T-unit) and Error-free clauses (EFC). Wigglesworth and Storch (2009) have defined T-unit as "an independent clause and all its attached or embedded dependent clauses" (p. 464).

Complexity, as is stated by Ellis (2009), includes both grammatical complexity and lexical complexity. Syntactic complexity was established through the calculation of the ratio of clauses per T-units in the participants' production (Ellis \& Yuan, 2004; Foster \& Skehan, 1996; Larsen-Freeman, 2006; Wigglesworth \& Storch, 2009). According to Foster and Skehan (1996), it is a reliable measure of complexity. Lexical complexity was operationalized as the ratio of mean segmental type-token (MSTTR). Following Ellis and Yuan (2004), at first, the narrative productions were divided into segments of 40 words and the type-token ratio of each segment was computed through dividing the total number of different types of words by the total number of words in the segment. Then, the MSTTR was computed by adding the mean score of the segments and dividing the total by the total number of segments in the narrative text for each participant.

Skehan and Foster (1999) have argued that global units represent a more realistic measure of accuracy. Thus, the accuracy of the writing texts was measured by calculating the number of error-free T-units divided by the total number of T-units (EFT/T) (Larsen- Freeman, 2006; Wigglesworth \& Storch, 2009). An additional measure of accuracy was the proportion of error-free clauses of all clauses $(\mathrm{EFC} / \mathrm{C})$. Both proportions were expressed as percentages (Ellis \& Yuan, 2004; Larsen-Freeman, 2006; Wigglesworth \& Storch, 2009). Spelling errors were tolerated as far as the meanings of words were preserved. Once counted, they were not taken into account if they were repeated on later occurrences. Errors of capitalization, prepositions, punctuation and errors of lexical choices were not counted unless they hindered comprehension (ibid.).

\section{Results}

The SPSS, version20, was utilized in order to calculate and analyze the collected data.

\subsection{Nelson English Proficiency Test}

The Nelson (300D) English proficiency test was given as a homogeneity test to ensure the homogeneity of the two groups at the outset of the study. As Table 4.1 illustrates, the mean score (standard deviation) of the experimental group was 36.30 (4.08). For the control group, the mean score (SD) of 35.65 (3.30) was achieved.

Table 1. Statistics of Nelson English Proficiency Test Scores

\begin{tabular}{|c|c|c|c|c|c|c|c|c|c|c|}
\hline Groups & $\mathrm{N}$ & Minimum & Maximum & Mean & $\begin{array}{c}\text { Std. } \\
\text { Deviation }\end{array}$ & \multicolumn{2}{|c|}{$\begin{array}{c}\text { Levene's Test for } \\
\text { Equality of } \\
\text { Variances }\end{array}$} & \multicolumn{3}{|c|}{$\begin{array}{c}\text { t-test for Equality of } \\
\text { Means }\end{array}$} \\
\hline Experimental & 20.00 & 30.00 & 45.00 & 36.30 & 4.08 & .37 & .57 & .55 & 38.0 & .58 \\
\hline Control & 20.00 & 31.00 & 43.00 & 35.65 & 3.30 & & & & 0 & \\
\hline
\end{tabular}


Equality of variances is one of the pre-requisite points needed for the inferential analysis through independent samples $t$-test. To this end, the Levene's test was run to compute the variances for the two groups, which showed a nonsignificant value $(p=.57>.05)$. Based on the result of the $t$-test (Table 1), it could be concluded that both groups were similar regarding their general English proficiency prior to the specific treatment, since no statistically significant group differences were found in their Nelson proficiency test scores $(t(38)=.55, p=.58>.05)$.

\subsection{The Pre-test}

With respect to the measures of complexity and accuracy, the obtained results from the pre-test are reported in Table 2. Regarding the measure of syntactic complexity, namely the proportion of clauses to T-units, the experimental group had the mean (SD) of 1.73 (.06). In the similar vein, the control group had the mean (SD) of 1.70 (.05). For the lexical complexity of the writing performance, MSTTR, there was a mean (SD) of .61 (.03) and .60 (.04) for the experimental and control groups, respectively.

In terms of the first measure of accuracy, namely the percentage of EFTs, as shown in Table 2, the mean (SD) of the experimental and control groups were $.45(.04)$ and $.45(.04)$, respectively. For the second measure of accuracy, i.e. the percentage of EFCs, the mean (SD) of the experimental group turned to be .59 (.05) and for the control group it was .57 (.04).

Table 2. Statistics of the Complexity and Accuracy Measures on the Pre-test Scores

\begin{tabular}{|c|c|c|c|c|c|c|c|c|c|c|c|c|}
\hline & \multirow[t]{2}{*}{ Variables } & \multirow[t]{2}{*}{ Groups } & \multirow[t]{2}{*}{$\mathrm{N}$} & \multirow[t]{2}{*}{ Minimum } & \multirow[t]{2}{*}{ Maximum } & \multirow[t]{2}{*}{ Mean } & \multirow[t]{2}{*}{$\mathrm{SD}$} & \multicolumn{2}{|c|}{$\begin{array}{c}\text { Levene's Test for } \\
\text { Equality of } \\
\text { Variances }\end{array}$} & \multicolumn{3}{|c|}{$\begin{array}{c}\text { t-test for Equality of } \\
\text { Means }\end{array}$} \\
\hline & & & & & & & & $\mathrm{F}$ & Sig & $\mathrm{t}$ & df & Sig \\
\hline \multirow{2}{*}{ 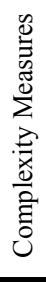 } & $\begin{array}{c}\text { 1.Clauses per T- } \\
\text { units }\end{array}$ & $\begin{array}{c}\text { Experimental } \\
\text { Control }\end{array}$ & $\begin{array}{l}20.00 \\
20.00\end{array}$ & $\begin{array}{l}1.60 \\
1.62\end{array}$ & $\begin{array}{l}1.82 \\
1.80\end{array}$ & $\begin{array}{l}1.73 \\
1.70\end{array}$ & $\begin{array}{l}.06 \\
.05\end{array}$ & 1.97 & .17 & 1.63 & 38.00 & .11 \\
\hline & 2.MSTTR & $\begin{array}{c}\text { Experimental } \\
\text { Control } \\
\end{array}$ & $\begin{array}{l}20.00 \\
20.00 \\
\end{array}$ & .55 & $\begin{array}{l}.65 \\
.65 \\
\end{array}$ & $\begin{array}{l}.61 \\
.60 \\
\end{array}$ & $\begin{array}{l}.03 \\
.04 \\
\end{array}$ & 1.79 & .19 & .84 & 38.00 & .41 \\
\hline \multirow{2}{*}{ 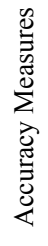 } & 1.\%of EFT & $\begin{array}{c}\text { Experimental } \\
\text { Control }\end{array}$ & 20.00 & .40 & .53 & .45 & $\begin{array}{l}.04 \\
.04\end{array}$ & .20 & .66 & .29 & 38.00 & .77 \\
\hline & $2 . \%$ of EFC & $\begin{array}{c}\text { Experimental } \\
\text { Control }\end{array}$ & 20.00 & .50 & .64 & .59 & .04 & .32 & .58 & 1.30 & 38.00 & .20 \\
\hline
\end{tabular}

Before performing the $t$-test, one-sample Kolmogorov-Smirnov (K-S) test was applied to see whether or not the data were normally distributed. The results showed the normality in the distribution of the scores of the two complexity indices (Experimental group: $p_{1}=.58>.05, p_{2}=.62>.05$; Control group: $p_{1}=.99>.05, p_{2}=.32>.05$ ) and accuracy measures (Experimental group: $p_{I}=.42>.05, p_{2}=.20>.05$; Control group: $p_{1}=.60>.05, p_{2}=.80>.05$ ) for the both groups. In addition, based on the results of Levene's tests, the $p$-value was calculated to be higher than the significance level of .05 in all the measures of complexity and accuracy; hence, the hypotheses concerning the equality of variances were confirmed. Bearing these in mind, the independent samples $t$-tests were run. The results of the $t$-tests revealed that there was no significant difference between the groups in terms of complexity measures $\left(t_{1}(38)=1.63, p_{I}=.11>.05 ; t_{2}(38)=.84\right.$, $\left.p_{2}=.41>.05\right)$. The result of the $t$-tests also indicated the $p$-value of .77 in the first measure of accuracy and .14 in the second measure of accuracy, both of which were higher than .05 . Therefore, the hypotheses concerning the equality of means were tenable, and there was not any significant difference between the performance of the experimental and control groups in the case of complexity and accuracy in performing the pre-test narrative writing task.

\subsection{The Post-test 1}

Based on the descriptive statistics for the measures of complexity in the post-test 1, as illustrated in Table 3, the experimental group was supposed to be more complex task performer than the control group (Experimental Group: $\mathrm{M}_{1}$ $=1.88, \mathrm{SD}_{1}=.05 ; \mathrm{M}_{2}=.74, \mathrm{SD}_{2}=.05 ;$ Control Group: $\mathrm{M}_{1}=1.70, \mathrm{SD}_{1}=.07 ; \mathrm{M}_{2}=.60, \mathrm{SD}_{2}=.04$ ). As for the accuracy measures, the experimental group's performance $\left(\mathrm{M}_{1}=.45, \mathrm{SD}_{1}=.04 ; \mathrm{M}_{2}=.59, \mathrm{SD}_{2}=.05\right)$ was highly similar to the control group's performance $\left(\mathrm{M}_{1}=.45, \mathrm{SD}_{1}=.04 ; \mathrm{M}_{2}=.57, \mathrm{SD}_{2}=.04\right)$. However, the $t$-tests were run to explore whether the differences were significant or not.

As is represented in Table 3, the results of Levene's tests confirmed the equality of variances for both data sets of complexity $\left(p_{1}=.49>.05 ; p_{2}=.66>.05\right)$ and accuracy $\left(p_{1}=.63>.05 ; p_{2}=.63>.05\right)$. Additionally, the groups were checked for the normality in the distribution of the scores in the both measures of complexity and accuracy through one-sample K-S 
tests, the results of which revealed non-significance value $(>.05)$ for both groups in the complexity (Experimental group: $p_{I}=.60>.05, p_{2}=.89>.05$; Control group: $p_{1}=.36>.05, p_{2}=.49>.05$ ) and accuracy indices (Experimental group: $p_{1}=.41>.05, p_{2}=.26>.05$; Control group: $p_{1}=.94>.05, p_{2}=.74>.05$ ) which meant that the distribution of the scores was normal in the groups.

The results of the $t$-tests showed that there was statistically significant difference between the two groups in terms of complexity measures (syntactic complexity: $p=.00<.05$; lexical complexity: $p=.00<.05$ ) which confirmed that the differences between the groups were significant. However, the results for each accuracy indices revealed that although the experimental group, to some extent, had a more accurate output than the control group; the differences were not significant, since the $p$-value in all the measures of accuracy was higher than .05 level of significance.

Table 3. Statistics of the Complexity and Accuracy Measures on the Post-test 1 Scores

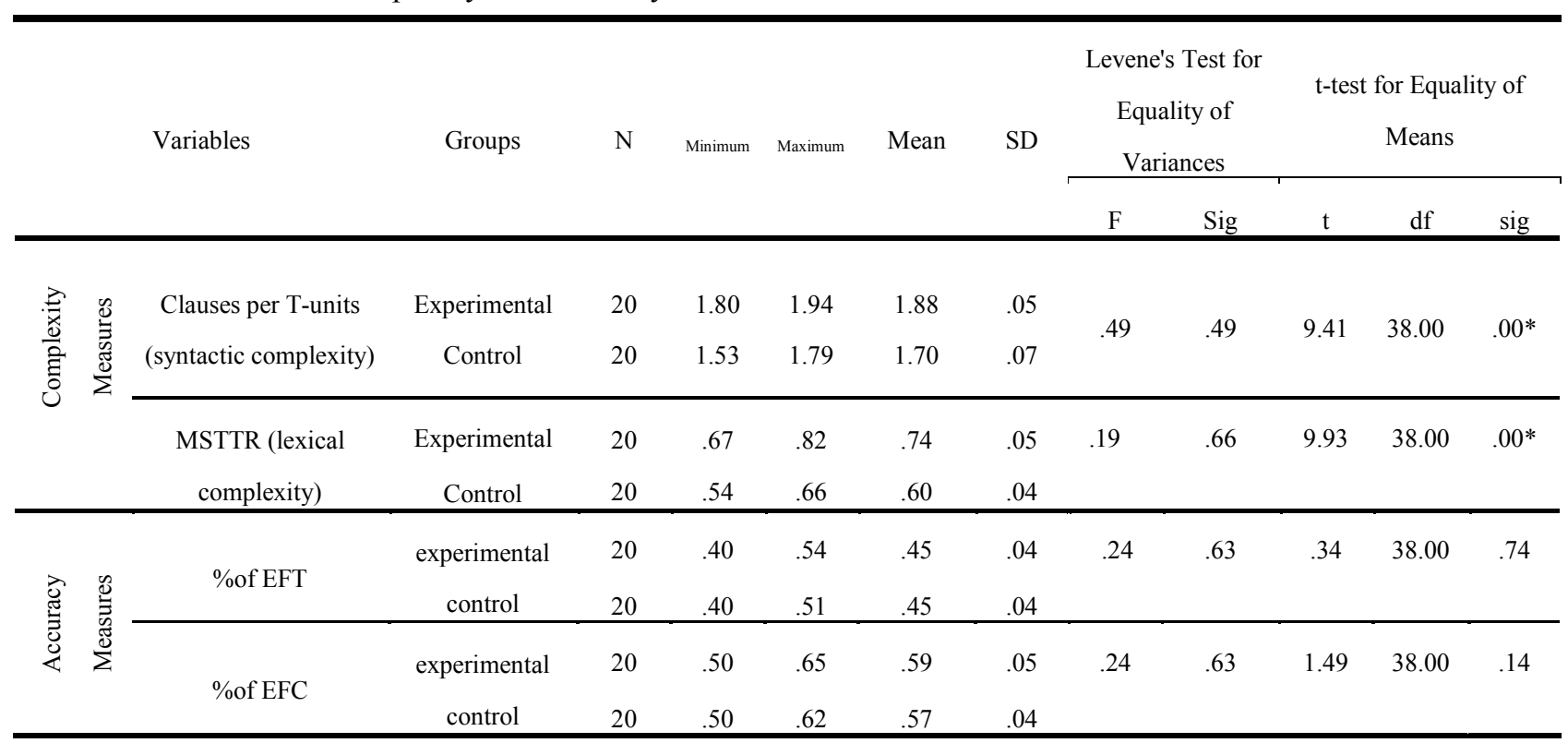

*: Differences are significant at the .05 level (2-tailed).

\subsection{The Post-test 2}

As is clear in Table 4, with respect to the measure of syntactic complexity, the proportion of clauses to T-units, there is a mean (SD) score of 1.82 (.05) for the experimental group, and the mean (SD) score of 1.56 (.06) in the case of the control group. Similarly, concerning lexical complexity measure, the experimental group gained a higher mean $(\mathrm{M}=.85$, $\mathrm{SD}=.04)$ than the control group $(\mathrm{M}=.69, \mathrm{SD}=.04)$. In regard with accuracy measures in the post-test 2 , the mean scores of the experimental group $\left(\mathrm{M}_{1}=.59, \mathrm{SD}_{1}=.04 ; \mathrm{M}_{2}=.64, \mathrm{SD}_{2}=.06\right)$ was fairly greater than that of the control group $\left(\mathrm{M}_{1}=.57, \mathrm{SD}_{1}=.05 ; \mathrm{M}_{2}=.61, \mathrm{SD}_{2}=.06\right)$.

Table 4. Statistics for the Complexity and Accuracy Measures on the Post-test 2 Scores

\begin{tabular}{|c|c|c|c|c|c|c|c|c|c|c|c|c|c|}
\hline & & \multirow[t]{2}{*}{ variables } & \multirow[t]{2}{*}{ Groups } & \multirow[t]{2}{*}{$\mathrm{N}$} & \multirow[t]{2}{*}{ Minimum } & \multirow[t]{2}{*}{ Maximum } & \multirow[t]{2}{*}{ Mean } & \multirow[t]{2}{*}{ SD } & \multicolumn{2}{|c|}{$\begin{array}{c}\text { Levene's Test } \\
\text { for Equality of } \\
\text { Variances }\end{array}$} & \multicolumn{3}{|c|}{$\begin{array}{c}\text { t-test for Equality of } \\
\text { Means }\end{array}$} \\
\hline & & & & & & & & & $\mathrm{F}$ & Sig & $\mathrm{t}$ & df & Sig \\
\hline \multirow{4}{*}{ 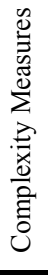 } & & Clauses per T- & Experimental & 20.00 & 1.76 & 1.92 & 1.82 & .05 & \multirow{2}{*}{.41} & \multirow{2}{*}{.52} & \multirow{2}{*}{15.12} & \multirow{2}{*}{38.00} & \multirow{2}{*}{$.00^{*}$} \\
\hline & & units & Control & 20.00 & 1.46 & 1.69 & 1.56 & .06 & & & & & \\
\hline & \multirow{2}{*}{\multicolumn{2}{|c|}{ MSTTR }} & Experimental & 20.00 & .78 & .92 & .85 & .04 & .29 & .59 & 12.23 & 38.00 & $.00^{*}$ \\
\hline & & & Control & 20.00 & .62 & .76 & .69 & .04 & & & & & \\
\hline \multirow{4}{*}{ 冚 } & \multirow{4}{*}{ 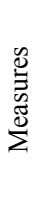 } & \multirow{2}{*}{$\%$ of EFT } & experimental & 20.00 & .53 & .64 & .59 & .04 & \multirow[t]{2}{*}{2.80} & \multirow[t]{2}{*}{.10} & \multirow[t]{2}{*}{1.78} & \multirow[t]{2}{*}{38.00} & \multirow[t]{2}{*}{.08} \\
\hline & & & control & 20.00 & .50 & .64 & .57 & .05 & & & & & \\
\hline & & \multirow{2}{*}{$\%$ of EFC } & experimental & 20.00 & .56 & .74 & .64 & .06 & \multirow[t]{2}{*}{.14} & \multirow[t]{2}{*}{.71} & \multirow[t]{2}{*}{1.41} & \multirow[t]{2}{*}{38.00} & \multirow[t]{2}{*}{.17} \\
\hline & & & control & 20.00 & .52 & .72 & .61 & .06 & & & & & \\
\hline
\end{tabular}

*: Differences are significant at the .05 level (2-tailed).

Regarding normality in the distribution of the data, the results of one Sample K-S tests indicated non-significance value $(>.05)$ for both groups in regard with syntactic complexity (Experimental group: $p=.76$; Control group: $p=.89)$ and 
lexical complexity (Experimental group: $p=.83$; Control group: $p=.79$ ); implying that the distribution of the scores was normal in the groups. Similarly, as far as the accuracy was concerned, the normality in the distribution of the data in the samples were established (Experimental group: $p_{I}=.48>.05, p_{2}=.19>.05$; Control group: $p_{I}=.80>.05, p_{2}=.38>.05$ ). In addition, the results of Levene's tests (Table 4), indicated the non-significant values (>.05), which meant that equality of variances were assumed.

As can be seen in Table 4, the results of independent samples $t$-tests for the measures of complexity showed a significant level of $p$-value $(<.05)$ for both the syntactic and lexical complexity measures $\left(t_{l}(38)=15.12, p_{I}=.00 ; t_{2}(38)\right.$ $=12.23, p_{2}=.00$ ). This implied that the experimental group had a significantly more complex performance than the control one. In regard with accuracy, the $p$-value for both measures of accuracy was higher than .05 level, which showed that there were not a significant differences between the both groups.

\section{Discussion and Conclusion}

The purpose of the study was to investigate the effect of engaging in repetitive practice of narrative writing tasks on the complexity and accuracy of the learners' second performance of the task that was done 10 weeks earlier. In addition, the study examined whether the effect of task repetition transferred to the performance of a new narrative task which was not performed before, and hence helped language development.

In regard with the first research question, the inferential analyses of the data demonstrated that complexity was significantly affected by this type of planning in a positive manner. Therefore, it was found that the learners, who were engaged in repetitive practice of narrative writing tasks, produced more complex narrative writing than those who were not. The explanation for this finding can be found in the theoretical model of writing outlined by Kellog (1996) and the idea of limited working memory capacity. Kellog (ibid.) has stressed that the writers activate formulation (including translation), execution, and monitoring processes at the same time, although the extent to which this is achievable depends on their working memory.

In particular, Adams (2003) in line with Bygate and Samuda (2005) has assumed that the attentional resources for the translating and executing stages can be enhanced through task repetition. This is because an initial performance of the task ensures the learners' attentional demands of task content, and leads to a more capacity for linguistic encoding and articulation. Consequently, attention would be on L2 form, and complexity is one aspect of the language form which may be improved in this way. The findings of the previous related studies (Bygate, 2001; Gass et al., 1999; LarsenFreeman, 2006), regarding the effect of task repetition on complexity are confirmed in this study.

Concerning the second research question, with respect to the two measure of accuracy, the obtained results illustrated that task repetition had no significant effect on the experimental group in producing more accurate language (in both accuracy indices, $p>.05$ ). This finding is supported by Skehan's (1998) account of the trade-off hypothesis. Based on this hypothesis, different aspects of language performance compete for limited memory capacity during the processing, and in so doing, attention to one aspect leads to a decreased attendance to the other aspects.

According to Skehan (1998) the trade-off effect is mostly between complexity and accuracy. Thus, if learners prioritize complexity in performing the tasks, accuracy will be suffered. The finding is in line with Bygate (2001), and Gass et al.'s (1999) study, which showed no significant improvement in accuracy after repetitive practice treatment. According to Kawauchi (2005) low proficient EFL learners may have the greatest room for accuracy improvement in comparison with high-intermediate and advance level learners.

The last and third research question addressed the transference of task repetition effect to a new narrative writing task. Based on the obtained results from the inferential statistics, it was found that the experimental group produced significantly more complex language. However, there was not any significant difference between the experimental and control groups in the case of accuracy in the new narrative writing task performance. Therefore, it was concluded that while task repetition had no significant effect on the accuracy of the new narrative task performance, it did have a significant effect on complexity of the new narrative task performance.

The findings provide further evidence for Skehan's (1998) trade-off hypothesis. The underlying assumption is that limited working memory capacity prevents learners to pay attention to all aspects of language performance equally, and requires them to pay attention to one aspect of performance at the cost of the others (ibid.). Thus, it can be suggested that the complexity has improved at the cost of accuracy in this study. The gains in complexity in performing the new narrative task support Moser's (2012) argumentation that gains in language complexity can be considered as a sign of the learner's language development. This is because it demonstrates the learners' willingness and ability to stretch their interlanguage, which ultimately facilitates interlanguage development. However, this study cannot provide support for Skehan et al.'s (2012) idea that developing greater accuracy entails rehearsal through task repetition, since there was not any significant gain in accuracy of the group engaged in repetitive practice in this study.

The findings are in contrast with Bygate (2001) and Gass et al.'s (1999) argumentation that there is no transference of the effect of practicing the same task type to a new task performance, even when it is the same type as the original task. Furthermore, with respect to gains in complexity, the finding is in agreement with Zohrabi and Abasvand's (2014) finding. However, when the gains in accuracy are concerned, the result of this study is in contrast with theirs, since they have found no trade-off effect between complexity and accuracy, which is evident in the findings of this study.

Overall, it might be concluded that task repetition does impact significantly the complexity- but not accuracy- of the narrative writing performance. Moreover, the effect of task repetition in regard with the gains in complexity, extended to the performance of a new narrative task, and thereby, contributes to interlanguage development. Hence, with regard to the pedagogical perspective, task repetition may afford high-intermediate EFL learners the opportunity to compensate 
for their limited cognitive processing capacity, in performing the cognitively demanding narrative writing tasks in order to have a more complex performance. Also, it may help them to notice their language-related shortcomings, which ultimately lead to developments in their interlanguage. Accordingly, it appears crucial for instructors to include repetitive practice of the tasks in their EFL writing teaching programs in order to afford learners the opportunity to attend to both meaning and form.

However, it should be noted that the number of the participants of this study was limited to only 40 female highintermediate EFL learners in Iran. Thus, the findings of this study cannot be generalized to all EFL learners and contexts, because the sample population is not representative of the total number of English learner population with different age, gender, and levels of English proficiency. Future studies may analyze the writing performance intensively in terms of discourse features in order to be a good indicator of the quality of writing performance. It would also be important to investigate the interaction of task repetition with some additional treatments such as providing teacher/learner feedback, comparing the productions with native output, working in pairs, etc., which may help learners to overcome the trade-off effects that exist between complexity and accuracy in their performance. Also, further studies may need to tackle the effect of task repetition on other different modes of writing such as expository or argumentative ones, which may reveal different results in regard with the quality of writing performance.

\section{Acknowledgment}

This paper is based on an ELT M.A. thesis, completed at Islamic Azad University of Ahar branch, Ahar, Iran.

\section{References}

Adams, R. (2003). L2 output, reformulation and noticing: Implications for IL development. Language Teaching Research, 7(3), 347-376. DOI: 10.1191/13621688031r127oa. Retrieved March 6, 2013, from http://tr.sagepub.com/content/7/3/347.html.

Ahmadian, M. J. (2011). The effect of 'massed' task repetitions on complexity, accuracy, and fluency: Does it transfer to a new task?. The Language Learning Journal, 39(3), 269-280. DOI:10.1080/09571736.

Biria, R. \& Jafari, S. (2013). The impact of collaborative writing on the writing fluency of Iranian EFL learners.Journal of Language Teaching and Research,4(1), 164-175. DOI:10.4304/j1tr.4.1.164-175.

Birjandi, P. \& Malmir, A. (2009). The effect of task based approach on the Iranian Advanced EFL learners' narrative vs. expository writing. Iranian Journal of Applied Language Studies, 1(2), 1-26.

Bygate, M. (1999). Task as the context for the framing, reframing and unframing of language. System, 27, 33-48.

Bygate, M. (2001). Effects of task repetition on the structure and control of oral language. In M. Bygate, P. Skehan, \& M. Swain (Eds.), Researching pedagogic tasks: Second language learning, teaching, and testing (pp. 23-48). Harlow, UK: Longman.

Bygate, M. \& Samuda, V. (2005). Integrative planning through the use of task repetition. In R. Ellis (Ed.), Planning and task performance in a second language (pp. 37-74). Amsterdam: John Benjamins.

Chastain, K. (1988). Developing second language skills: Theory and practice. New York, NY: Harcourt Brace Jovanovich, Inc.

Eliasi, A. \& Vahidi Borji, H. (2013). Task repetition and noticing as a route to semester-long destabilization: A crosssectional study of Iranian EFL learners' oral output. International Journal of Applied Linguistics \& English Literature, 2 (3), 21-28. DOI:10.7575/aiac.ijalel.v.2n.3p.21.

Ellis, R. (2003). Task-based language learning and teaching. Oxford: Oxford University Press.

Ellis, R. (2005). Planning and task-based performance: Theory and research. In R. Ellis (Ed.), Planning and task performance in a second language (pp. 3-34). Amsterdam: John Benjamins Publishing Company.

Ellis, R. (2009). The differential effects of three types of task planning on the fluency, complexity, and accuracy in L2 oral production. Applied Linguistics, 30 (4), 474-509. DOI:10.1093/applin/amp042.

Ellis, R. \& Yuan, F. (2004). The effects of planning on fluency, complexity, and accuracy in second language narrative writing. Studies in Second Language Acquisition, 26, 59-84. DOI: 10.1017/S0272263104261034.

Foster, P. \& Skehan, P. (1996). The influence of planning on performance in task-based learning. Studies in Second Language Acquisition, 18(3), 299-324. DOI:10.1017/S0272263100015047.

Fowler, W. S. \& Norman, C. (1976). Nelson English language tests. Canada: Thomas Nelson and Sons Ltd.

Gass, S., Mackey, A., Fernandez, M., \& Alvarez-Torres, M. (1999). The effects of task repetition on linguistic output. Language Learning, 49, 549-580. DOI:10.1111/0023-8333.00102.

Hamadouche, M. (2010). Developing the writing skill through increasing learner's awareness of the writing process: The case of second year students. (Unpublished Master's thesis). EntouriUniversitty: Constantine.

Harris, D. P. (1969).Testing English as a second language. New York, NY: McGraw-Hill.

Heaton, J. (1975). Beginning composition through pictures. London: Longman. 
Howrey, J. D. \& Tanner, P. (2009). Writing portfolios: Empowering students, teachers, and the curriculum. In A. M. Stoke (Ed.), JALT2008 Conference Proceedings (pp. 1157-1167). Tokyo: JALT. Retrieved May 12, 2013, from http://jaltpublications.org/recentpdf/proceedings/2008/E087.

Kawauchi, C. (2005). The effects of strategic planning on the oral narratives of learners with low and high intermediate L2 proficiency. In R. Ellis (Ed.), Planning and task performance in a second language (pp. 143-164). Amsterdam: John Benjamins Publishing Company.

Kellogg, R. T. (1996). A model of working memory in writing. In C. M. Levy \& S. Ransdell (Eds.), The science of writing: Theories, methods, individual differences and applications (pp. 57-71). Mahwah, NJ: Lawrence Erlbaum.

Kim, S. H. (2001). A description of college students' writing process: A strategy-based approach. English Teaching, 56, $55-73$.

Larsen-Freeman, D. (2006). The emergence of complexity, fluency, and accuracy in the oral and written production of five Chinese learners of English. Applied Linguistics, 27(4), 590- 619. DOI:10.1093/applin/aml029.

Mackey, A. \& Gass, S. M. (2005). Second language research: Methodology and design. Mahwah, NJ: Lawrence Erlbaum Associates.

Moser, J. (2012). A classroom based, mixed methods study into the influence of transcribing, reporting, and task repetition: How do they impact in-class student spoken task performances (Unpublished doctoral thesis). University of Birmingham: United Kingdom.

Muranoi, H. (2007). Output practice in the L2 classroom. In R. M. Dekeyser (Ed.): Practice in a second language: Perspectives from applied linguistics and cognitive psychology (pp. 51-84). Cambridge: Cambridge University Press.

Silva, T. (1990). Second language composition instruction: Developments, issues and directions in ESL. In T. Silva \& P. Matsuda (Eds.), Landmark essays on ESL writing (pp.191-208). NJ: Hermagoras Press.

Skehan, P. (1998). A cognitive approach to language learning. Oxford: Oxford University Press.

Skehan, P., \& Foster, P. (1999). The influence of task structure and processing conditions on narrative retellings. Language Learning, 49(1), 93-120. DOI:10.1111/1467-9922.00071.

Skehan, P., Xiaoyue, B., Qian, L., \& Wang, Z. (2012). The task is not enough: Processing approaches to task-based performance. Language Teaching Research, 16(2), 170-187. DOI: 10.1177/1362168811428414.

Tavakoli, P. \& Skehan, P. (2005). Strategic planning, task structure, and performance testing. In R. Ellis (Ed.), Planning and task performance in a second language (pp. 239-73). Amsterdam: John Benjamins.

Wigglesworth, G. \& Storch, N. (2009). Pair versus individual writing: Effects on fluency, complexity and accuracy. Language Testing, 26(3), 445-466. DOI: 10.1177/0265532209104670.

Zoghi, M. (2012). Letscross the rubicon: Strengthening reading comprehension instruction. Procedia - Social and Behavioral Sciences, 70 (2013), 537- 543. DOI: 10.1016/j.sbspro.2013.01.091

Zohrabi, M. \& Abasvand, Y. (2014). The effects of task repetition on improving Iranian EFL learners' accuracy and complexity in writing proficiency. International Journal of English and Education, 3(2), 156-165. 